\title{
Felipe Delgado, otro de los Robinsones
}

Javier Sanjinés C.

University of Michigan

\begin{abstract}
Robinson Crusoe, the extraordinary ship-wrecked protagonist of Defoe's novel, is actually a modern transfiguration of the old myth of the "savage man," a myth that this article revisits. Robinson is brought by Defoe into a savage existence because the author intends to demonstrate that it is possible to defeat savagery in one's own land, turning Robinson into the virtuous and modern homo economicus. But there are other Robinsons that challenge the original: that of Jean-Jacques Rousseau, and the urban Robinson, conceived in novelistic form by Antonio Muñoz Molina. Both serve as models for my reading of Felipe Delgado as a novel that exemplifies the marginal Robinson. As happens to some of the characters in Antonio Muñoz Molina's novels, the Bolivian poet and novelist Jaime Saenz creates an urban, marginalized and eccentric Robinson that, unlike the previous mentioned, without a rational goal motivating him, secretly celebrates his incurable shipwrecks. Felipe is the Robinson born out of the lucid necessity of alcohol. Clairvoyant and repentant of his future, he is born for the night, a space and time that permits him to delve into the heart of the memory of his city.
\end{abstract}

Keywords

City, logical obversion, marginality, memory, underground 


\section{Resumen}

Robinson Crusoe, el extraordinario náufrago de la novela de Defoe, es en realidad una transfiguración moderna del viejo mito del hombre salvaje que este trabajo decide reavivar. Robinson es llevado por Defoe a una existencia salvaje porque debe demostrar que es posible derrotar al salvajismo en su propio terreno, transformándolo en el virtuoso homo economicus de la modernidad. Pero existen otros Robinson que cuestionan el original: el de Jean-Jacques Rousseau, y el Robinson urbano, pensado desde la novelística de Antonio Muñoz Molina. Ambos me sirven para elaborar la lectura del Felipe Delgado como la novela del Robinson marginal. Como les ocurre a algunos personajes de la novelística de Antonio Muñoz Molina, el poeta y novelista boliviano crea un Robinson urbano marginal y excéntrico que, a la deriva, sin meta racional que lo motive, conmemora secretamente sus naufragios incurables. Felipe es el Robinson de la necesidad lúcida del alcohol. Clarividente arrepentido de su porvenir, nace para la noche, espacio y tiempo que le permite hurgar en el corazón de la memoria de su ciudad.

\section{Keywords}

Ciudad, marginalidad, memoria, obversión lógica, subterraneidad

Al interior de la narrativa andina de la segunda mitad del siglo pasado, la obra de Jaime Saenz, particularmente su novela Felipe Delgado, resalta como uno de los más originales universos imaginarios. Pero esta novela no destaca precisamente por la originalidad de su estructuración, ${ }^{1}$ sino por la presencia de los inusuales personajes que habitan esa La Paz aymara, excéntricamente retratada por el autor. Felipe Delgado es única en plantear la marginalidad aymara desde el lenguaje solemne, acartonadamente teatral y risible, que regula los actos de habla de los personajes. Apartada del sentido común de las cosas, y parodiando la racionalidad de los argumentos claros y bien definidos, la novela de Saenz, poco estudiada fuera de Bolivia, ocupa, sin embargo, un lugar importante en la literatura andina contemporánea.

\footnotetext{
${ }^{1}$ La novela no revela ciertos rasgos fundamentales de la narrativa moderna: por ejemplo, la crisis moral que Felipe Delgado muestra en algunos pasajes de la obra, nada tiene de parecida a los tortuosos flujos de conciencia de los personajes de Dostoievski. Tampoco se nota interés en crear discursos indirectos libres como los que tienen las novelas de Faulkner y de Joyce. Ausentes también están las múltiples voces que dan lugar a la narración polifónica.
} 
Dedicado a mostrar el lado oscuro de la ciudad, Saenz da proporciones mágicas a La Paz, abriéndonos los ojos a un mundo subterráneo, habitado por hechiceros y cargadores beodos -los incomparables "aparapitas" - que posibilitan la búsqueda mística, tornando obsoleto el mundo de la realidad objetiva. No es que no exista dicha realidad en la novela - por ejemplo, el mundo que rodea a la tía Lía, quien recuerda a Felipe Delgado, el personaje, la necesidad de seguir una vida normal-, sino que el mundo racional y objetivo se debilita con el verdadero empeño en mostrarnos la excéntrica presencia de la muerte en vida, es decir, la extraña necesidad que Felipe tiene de "sacudirse este hechizo del vivir" (Saenz 22).

La inclinación por lo escatológico crea una estética peculiar que se desentiende del mundo viviente, es decir, del "mundo-para-la-vida". Saenz lo invierte, lo parodia, poniendo de cabeza las rutinas de la cotidianidad. De esta manera, la esencia de la vida, la esencia del ser, se transforma en un "estar" momentáneo e incierto, reñido con la materialidad de las cosas.

Saenz distingue entre el mundo hacia afuera, de la existencia fenoménica, y el mundo interior, hecho para la muerte. Puesto que concibe lo corporal como un mero "envoltorio" destinado a su desintegración, esta negación del mundo sensible y hecho para la vida muestra la lacerante escisión de un "yo" que desequilibra el principio de la identidad. Felipe intenta dialogar con la "presencia ausente" de su propio "yo", y concluye haciéndolo con un "tú" que se manifiesta a través de alucinaciones que son el resultado de la preocupación mórbida del personaje con la propia existencia. El universo poético de Saenz, también presente en su novela, plantea este "tú", la eterna espera del amor ausente - un "estarse" la llama el poeta- como el postergar indefinido de la identidad, una pulsión de muerte que domina a Felipe, protagonista de la extraña búsqueda.

Ahondar en la extraña naturaleza psicológica de este personaje me lleva a hablar de él como persona y como sujeto de un razonamiento lógico muy particular.

\section{Felipe Delgado y la obversión lógica}

Felipe, un hombre de veintiseis años, nace en la ciudad de La Paz, el año de 1903. Criado en el hogar de una familia de clase media alta, no llega a conocer a su madre porque ella muere en el momento del parto. Al cuidado de su padre, Virgilio Delgado, y de la tía Lía, hermana del padre, modelo de racionalidad y de sensatez humana, Felipe se educa bajo la tutela de profesores 
privados, algo frecuente en los sectores de clase alta de la época del liberalismo político y económico. El padre, que lleva una vida disipada, tiene también contactos con un mundo mágico, burlescamente extraño, manera de observar que el hijo va a heredar. Pero Virgilio es también un liberal pragmático, imbuido del librecambismo económico de su tiempo. Además de abogado, es un próspero rescatador de minerales.

La novela comienza con la muerte de Virgilio, en 1929, año de la gran crisis económica mundial, y un momento también delicado en la política boliviana que ha sufrido ya el derrumbe de los gobiernos liberales. Según observa el historiador Huáscar Rodríguez García (71), esta fecha marca uno de los momentos importantes de la reivindicación de la identidad chola que sacude Bolivia durante la primera mitad del siglo XX. Se trata de la reemergencia de lo mestizo, acontecimiento que da forma y posibilita la versión boliviana del anarquismo. Felipe abraza esta causa y se declara seguidor del voluntarismo irracionalista del pensador Franz Tamayo, a quien califica de "genio de la raza aymara" y de "mago, adivino, profeta y brujo" (161).

Felipe, quien adhiere al "anarquismo nato" que distingue al migrante del campo que se forja en la ciudad, plantea argumentos enrevesados que revelan la clave de su ser. Ellos se fundan en una suerte de obversión lógica que, al partir de una proposición dada, infiere otra proposición cuyo sujeto es igual al planteado originalmente, pero cuyo predicado es ahora contradictorio, de tal manera que la propuesta inicial (proposición "A") se invierte en otra, ahora negativa (proposición "E"). Un ejemplo simple de dicha operación lógica se da en el encuentro que Felipe tiene con el aymara Juan de la Cruz Oblitas, profesor en Ciencias Magnas y Narturales, a quien, sin conocer, saluda confianzudamente jalándole del cachete (62). Ofendido, Oblitas emite la siguiente proposición: "Una mansa paloma no tolera que le pellizquen la cara"(63). Felipe responde con una obversión lógica: "Una paloma no tiene cara, y por mansa que fuera, no es posible pellizcarle la cara" (63). Este tipo de enunciados trastocados es constante en la trama de la novela. Llevados al extremo, ellos parodian la organización racional del mundo-para-la-vida, cambiándola frecuentemente por otro mundo: uno mágico, extraño y burlesco, regido por la no-visión ${ }^{2}$ de argumentos que revelan, como veremos más tarde,

\footnotetext{
2 Hablo de una no-visión próxima a la teoría de lo grotesco (Kayser 1963). Kayser explica que el mundo alienado (die entfremdete Welt) es uno de los rasgos más importantes de lo grotesco. En el arte genuinamente grotesco, sostiene, el mundo de todos los días
} 
el "grotesco jubiloso" de la explicaciones inesperadamente invertidas por la obversión lógica.

Es notoria en Felipe su naturaleza peripatética. Apenas comenzada la novela, el narrador lo define como un "caminante solitario" (11) que recorre las calles más conocidas del casco viejo de la ciudad, lleno de caserones a medio derruir y tejados a punto de desmoronarse. Felipe pasa el día entero caminando por la ciudad en un estado de embriaguez y de trance que la soledad acentúa y de noche continua bebiendo en la bodega de Corsino Ordóñez o retorna al cuarto en ruinas que tiene alquilado en la calle Catacora. En este intenso trajinar, el hombre solitario "renuncia a vivir, siguiendo vivo" (93), desentendiéndose del futuro, en un "estarse" entre el pasado y el presente que reaviva su extraño comportamiento. Al renunciar al futuro, "el vivir muere [...] en cambio la muerte se está, ella no puede morir" (93). En realidad, "la muerte no nace, ni vive, ni muere: simplemente se está" (93).

La conexión entre el pasado y el presente torna la vida citadina en una ayuda memoria de la niñez. La dialéctica temporal - el ir y venir entre el pasado y el presente- acerca al caminante con el flaneur (Benjamin 326) y con el "Robinson urbano" (Muñoz Molina 309).

Felipe Delgado es un hombre maduro que no deja de ser un niño perdido y deambulante. Figura que oscila entre el pasado y el presente, entre el exterior citadino y el interior embrujado de su ser, el personaje "se está" en la ciudad, pero al margen de ella. Vagabundo solitario, burgués porque la ciudad es su hogar, Felipe encuentra cobijo en "El Purgatorio", la bodega de Ordoñez, donde convive con otros seres extraños, excéntricos, entre los cuales resaltan los aparapitas beodos. Caminante, como lo define la novela más de una vez, se "pierde" en la ciudad a la que conoce desde la niñez. En este su caminar se le aparece repentina y repetidamente la figura del pestilente

\footnotetext{
se convierte repentinamente en un lugar extraño, desagradable, asediado por la ansiedad y el peligro, en el que los seres humanos se encuentran completamente desorientados.Como sucede en la obra de Kafka, Saenz estaría de acuerdo en afirmar que no es el miedo a la muerte lo que provoca una situación grotesca entre nosotros, sino la ansiedad acerca de la vida. Dicha ansiedad es producida por eventos que son la manifestación de un mundo invertido, puesto de cabeza, contrapuesto a todo racionalismo. Las propuestas grotescas dependen de la inoportuna impredictibilidad de los eventos de la misma manera en que la racionalidad depende del pensamiento sistemático. Consecuentemente, podríamos afirmar que lo grotesco aparece no solamente como un factor o un evento desagradable o repugnante, sino también como aquello que desafía la previsibilidad de los eventos. De este modo, lo grotesco está relacionado con la obversión lógica de los argumentos.
} 
viejo, presencia que no es invención ni recuerdo, sino un memento mori que se desliza fantasmagóricamente, como la calavera de Los Embajadores, de Holbein. Este descuidado y semihumano viejo puede ser el mismo diablo, o un fantasma disfrazado de tal. Entre aparecidos, Felipe transita como si fuese ese Robinson peludo de los grabados antiguos, solo en las calles como en una isla donde no viviera nadie más, tropezándose con un fantasma envuelto en harapos que hace sus necesidades en zaguanes, marcando su territorio por la intensidad del hedor que despide.

Llegado a la bodega, Felipe tiene un extraño compartir con otros seres de carne y hueso, excéntricos personajes, como el jorobado Peña y Lillo, que permanecen al fondo de esta madriguera, confabulados y solos en la lejanía de otra especie que retrocede al salvajismo lejano, pretérito, que parece renacer en las casonas repletas de cuartos semiderruidos, cual si fueren cuevas $u$ oquedades de rocas en las que se cobijarían los hombre primitivos o los náufragos.

Si acaso lo que menos cambia, a través de tantos lugares y tiempos, es la habitación en la que los humanos nos recluimos, ese cuarto es tan emblemático de nuestra soledad como la isla y el salvaje que tan profundamente quedaron inscritos en el imaginario de la modernidad. Roger Bartra, el conocido etnólogo mexicano, me ayuda a profundizar este tema con sus estudios de cómo el salvaje quedó inscrito en la mitología occidental moderna. Posiblemente los salvajes más populares e influyentes del siglo XVIII fueron los creados por Defoe, Jonathan Swift y Jean-Jacques Rousseau. Defoe y Rousseau servirán de telón de fondo a lo que a continuación explico.

Al repensar los sugerentes trabajos de Bartra, complementándolos con los ensayos novelados de Muñoz Molina, las páginas que siguen dividen el trabajo en tres partes. La primera, se apoya en Robinson Crusoe, el extraordinario náufrago de la obra de Defoe, una transfiguración moderna del mito del homo selvaticus que, como se verá, repercute en la literatura boliviana de finales del siglo XIX y principios del siglo pasado, con la aparición del homo economicus de la etapa liberal. Este Robinson, "funcional" al proyecto liberal, tiene la capacidad de superar el estado de naturaleza no solo en la práctica económica, sino también en la creación estética.

En la segunda parte, exploro la presencia de otro Robinson, esta vez "disfuncional" porque lo concibo como el reverso del Robinson imaginado por Defoe. Aclaro que se trata del salvaje de Rousseau, tal cual aparece en el Contrato Social, y no precisamente el ser bondadoso, civilizable y 
europeizable, que el filósofo retrata en el Emilio. En este sentido, me refiero al ser humano que vive moral y económicamente derrotado. Propongo que así como Rousseau complejiza el mito del homo sylvestris, la novela boliviana del "encholamiento", particularmente la de Medinaceli, crea una figuración literaria crítica de la sociedad burguesa. Robinsones disfuncionales, los personajes masculinos de la novela del cholaje y del encholamiento se visten con la desnudez del salvaje para abrigar su endeble existencia y protegerla de la intemperie cruel de la civilización moderna.

Por último, la tercera parte retorna a Felipe Delgado, el Robinson urbano que parodia al homo economicus de la modernidad. Me concentro en dos pasajes de la novela de Saenz para explorar la idea de que, ni funcional, ni disfuncional, el comportamiento de Delgado es una suerte de reflexión humana de la obversión lógica que parodia la modernidad, creando así un "grotesco jubiloso" que explico al final del trabajo.

\section{El Robinson funcional a la modernidad}

Robinson Crusoe, tenida como la primera novela inglesa, es también el documento histórico que inició el individualismo radical. Como Jonathan Franzen la describe (81), esta novela cuenta la historia de una persona cualquiera, capaz de sobrevivir, física y mentalmente, totalmente aislada de la sociedad. ${ }^{3}$ Dicha historia entreteje la glorificación del individuo industrioso con la expansión de la burguesía letrada, deseosa de escribir sobre sus propios

\footnotetext{
${ }^{3}$ La propuesta imaginaria en torno al individualismo a ultranza es central al realismo como corriente literaria que domina la cultura occidental durante tres siglos. La potente voz de Crusoe, cuyo eco se escucha en importantes novelas como Jane Eyre, El hombre invisible, o incluso en Roquentín, el personaje de la Náusea, de Sartre, ocupa también un lugar importante en The Rise of the Novel, de lan Watt, un ensayo ya clásico sobre el tema.

Surgida de las cenizas del tedio, segura de la superioridad de la civilización occidental, la novela realista establece la imperiosa necesidad de someter y apropiarse intelectualmente del mundo de la naturaleza, poblado por el "salvajismo" de "los otros", los colonizados, que no forman parte de la cultura occidental. En el corazón mismo del poderío colonial que Inglaterra ejerce sobre su territorio de ultramar, el siglo XIX transcurre bajo una mirada eurocéntrica que contempla el mundo de la naturaleza como algo que debe ser domesticado, explotado y sujeto al emprendimiento económico privado e individual. Y la supervivencia de Robinson en una isla desértica es el producto de un naufragio racional autodisciplinado, que se distingue de salvajes y de caníbales incapacitados de comprenderlo y que contrastan con la actividad del moderno homo economicus en formación.
} 
logros, y el ascenso social de una clase que supera el viejo orden estamental. Aparece entonces una gama de individuos aislados, solitarios, imaginativos y decididamente industriosos: son los Robinsones funcionales, que se adecuan al sistema de intercambio mercantil, y que merecen nuestra atención.

En sendos libros sobre el mito del salvaje europeo, y sobre la forma en que mutan a partir de los albores de la civilización occidental, Roger Bartra explica que el siglo XVIII comienza con un misterio: ¿Por qué Defoe presenta a su Robinson, el ejemplo más importante del nuevo homo economicus capitalista, reducido al estado de naturaleza, es decir, a su condición de homo sylvestris? Bartra encuentra la respuesta en el hecho de que Robinson no ejemplifica el retorno a una feliz edad de oro, a un vergel medieval imaginado por el tópico del locus amoenus, sino al estado bestial que el náufrago es capaz de superar gracias a la Providencia divina. Robinson supera una prueba que los monjes anacoretas ya ensayaron cuando se retiraron al desierto para enfrentarse a demonios y a tentaciones. Ambos casos coinciden en experimentar la condición del salvaje, pero sin caer en el salvajismo. (Bartra 363). Salvaje que no pierde la naturaleza de la condición burguesa adquirida, Robinson representa al homo economicus que, a pesar de las peripecies sufridas, "no ve disipada su ascética eficiencia" (363). En efecto, Robinson no solo sufre una degeneración salvaje, sino que alcanza su realización individual cuando organiza su vida con la mentalidad del economista que sabe de haberes y de débitos; del tiempo-trabajo que implican las actividades humanas, al igual que la meticulosidad que supone ponerle precio a la mercancía. Como el hombre nuevo que es, el Robinson funcional exalta el individualismo bajo la forma del ascetismo protestante que hace del individuo la mediación entre Dios y el hombre. Esta explicación de corte weberiano también ayuda al historiador inglés James Dunkerley a enfatizar la función del ascetismo burgués puritano como la forma de la espiritualidad capitalista. ${ }^{4}$ Al cruzar las observaciones de Dunkerley sobre Crusoe con sus importantes aportes a

\footnotetext{
${ }^{4}$ En Crusoe And His Consequences, Dunkerley introduce un interesante análisis de Ian Watt, como persona y como crítico de Defoe. Según nos revela Dunkerley, Watt aprende en carne propia, como prisionero de los japoneses en Burma, a fortalecer el espíritu en las condiciones más adversas. Esta experiencia le lleva a comprender mejor la naturaleza de Robinson Crusoe. Ubicado en su isla de la soledad, es una mera posibilidad de que el individuo lleve a cabo sus potencialidades. Que ello se dé, depende de que éste entreteja la ética protestante con la soledad arquetípica de nuestra civilización: el homo economicus. En esta soledad ascética y puritana -muy distante de la piedad de los ermitaños y de los místicos de la cristiandad-Robinson se vuelve el espléndido ejemplo de la ética del capitalismo.
} 
propósito del análisis histórico de la modernidad boliviana, me parece oportuno aproximar el homo economicus robinsoniano a esta otra realidad.

¿Cómo se escucha la potente voz de Crusoe al interior de la tradición boliviana? En su libro Entre caudillos y multitudes. Modernidad estética y esfera pública en Bolivia, siglos XIX y XX, Roberto Pareja emprende la tarea de ubicar al Robinson boliviano. Perdido en las serranías mineras, el autor halla a José Avelino Aramayo, ejemplo paradigmático del homo economicus en "su proceso de subjetivación" (14). Pareja nos informa que ciertas biografías encuentran al notable industrial minero en el proceso de plasmación de su "yo". "En los márgenes de la comunidad", escribe Pareja, las biografías escritas sobre este notable barón del estaño lo ubican "aislándolo de sus semejantes, como el profeta que se retira al desierto antes de regresar a predicar la buena nueva de la modernidad" (14).

Verdadero apóstol de la nueva etapa económica, que surge durante la segunda mitad del siglo XIX, Aramayo sería, en la vida real, el mejor ejemplo del homo economicus solitario, del Robinson industrioso. Sin figurar en la política, ni desempeñar cargos urbanos, este ser aislado, perdido en el terreno agreste de la explotación del estaño, habría realizado, en la opinión de Carlos Medinaceli, "una tarea más útil y profunda, creando una industria nueva [...] o explotando, descubriendo y civilizando, ganando, incorporando las tierras abscónditas a la nacionalidad y a la economía social" (citado por Pareja 15). Pues bien, en la tarea de este gestor de la economía del estaño radicaría el momento de la creación del moderno homo economicus. En este ser solitario tendríamos al personaje histórico que representa, en Bolivia, "el devenir sujeto del individuo aislado de la economía política clásica, a la Robinson Crusoe" (Pareja 16).

Guiado por las biografías que Ernesto Rück y Carlos Medinaceli escribieron sobre Aramayo, Pareja ahonda más en el tema del homo economicus, del mito del hombre representativo de la modernidad. Motivado por dicho mito, se dedica, ahora en el plano estético, al estudio de La isla, novela de Manuel María Caballero, publicada en 1864, y poco conocida por la crítica literaria (69-98).

Publicada por entregas en la Aurora Literaria de Sucre, esta breve novela narra "los acontecimientos ocurridos en una isleta del lago Poopó adonde la familia Mendoza llega huyendo de las pasiones políticas" (Pareja 69). Prosigue Pareja: "El señor Mendoza, un veterano de las guerras de la independencia, su esposa y su hija Filomena escapan de la sociedad en la que hasta entonces han 
vivido y recrean en el aislamiento isleño una comunidad primigenia" (69).

Del relato de Pareja en torno al significativo aislamiento, rescato el retiro de esta familia, de su apartamiento de la comunidad política, como el momento del recogimiento previo que implica el retorno al estado de naturaleza. En este aislamiento voluntario o forzado, el ciudadano industrioso, el homo economicus, se va autoformando, autoeducando. Entre la meditación y el nuevo entrenamiento, se va produciendo, poco a poco, la reinserción del Robinson, del individuo industrioso, en la comunidad, "a través de la práctica de ciertas virtudes que, internalizadas en la subjetivación, luego son garantía de orden y progreso" (83).

La isla está relacionada explícitamente con el Robinson Crusoe de Defoe. En efecto, el narrador de la novela le pide al lector que lea a Defoe. Pareja observa acertadamente que el aislamiento en una isla desierta no tiene un valor exclusivamente económico, sino que el texto de Caballero, como Rousseau, "interpreta la función de la naturaleza en la isla a partir del aspecto educativo y formador de la contemplación estética de la naturaleza" (95). Comprendo muy bien este acercamiento a Rousseau, a través de la lectura del Emilio, que, en 1762, se refiere a la formación de un hombre, es decir, de su reforma, puesto que dicho proceso se inicia antes, con la novela de Defoe. Consciente de ello, ofrezco a continuación una manera diferente de aproximarnos a Rousseau, marcada, como se verá, por la existencia de otro Robinson, disfuncional, crítico de la posibilidad de unir lo utilitario con lo estético.

\section{El Robinson disfuncional y distópico}

Jean-Jacques Rousseau, uno de los primeros seguidores de Robinson Crusoe, propone en Émile que dicha obra sea el texto básico para la educación de los niños. Su propuesta está en la larga sección en la cual Robinson relata cómo sobrevive al naufragio y es capaz de permanecer en una isla desierta por un cuarto de siglo. Pero al seguir el estudio de Bartra, y de complementarlo con la lectura igualmente interesante de Dunkerley, me aparto del criterio de que Robinson ingresa en un retiro místico (Dunkerley 167). Su soledad es de otra naturaleza: ascética, puritana, abocada a un proceso de subjetivación más complicado que el que se advierte cuando se le relaciona con una tradición lluminista homogénea, la cual Rousseau habría supuestamente compartido durante el siglo XVIII. En tal sentido, me parece que su buceo en el 'yo' autobiográfico se diferencia del retorno al estado de naturaleza 
propuesto por los otros Philosophes del Siglo de las Luces, particularmente por Voltaire. ${ }^{5}$

A los treinta años, Rousseau es apreciado por los pensadores europeos que no llevan la voz cantante del lluminismo. Intentando formular un nacionalismo económico y cultural que observa con profundo resentimiento el universalismo cosmopolita de los franceses, jóvenes provincianos alemanes de la talla de Fichte y de Herder encuentran las ideas de Rousseau particularmente atractivas. $Y$ en esa conjunción del nacionalismo cívico francés con el nacionalismo étnico alemán, el homo economicus queda modificado, transformado por el Robinson disfuncional, en pugna con los principios ciudadanos que surgían del lluminismo metropolitano. Revolucionarios de provincia, como Robespierre, se inspiran en la esperanza rousseauniana de poder controlar la avaricia a través de una nueva estructura política que cure los males producidos por las desigualdades introducidas en la sociedad comercial. $^{6}$

\footnotetext{
${ }^{5}$ La gran aventura del siglo XVIII por lograr una civilización universal en armonía con el racionalismo económico, artístico y científico -particularmente el racionalismo de Voltaire y de Adam Smith-deja a Rousseau afuera del círculo de los pensadores privilegiados. En realidad, no existe otro pensador iluminista más receloso del proceso burgués que Rousseau. El ginebrino es un parvenu autodidacta, memorablemente descrito por Isaiah Berlin como el "más grande militante de clase baja de la historia" (citado por Mishra 68). En sus más importantes obras, como el Contrato social, Rousseau se empeña en mostrar la vanidad metropolitana, y en desconfiar de tenócratas, de comerciantes citadinos, y de sus costumbres morales. En otras palabras, recela del homo economicus que Adam Smith inventa.
}

Voltaire, con quien Rousseau tiene una violenta animosidad, lo caricaturiza como "un bellaco que quisiera ver estafados a los ricos para así lograr la igualdad de la humanidad" (Mishra 69). Rousseau describe la quintaesencial experiencia interior de la modernidad elitista sin realmente pertenecer a dicha élite, como un forastero que mira las cosas desde afuera, luchando por comprenderlas. Su mirada de la modernidad no puede dejar de observar una élite parisina envidiosa, ególatra y ensimismada. Todo ello muestra a Rousseau como un pensador excéntrico, obsesionado en las consecuencias psíquicas de la desigualdad. Puede decirse que es un profeta, un adelantado del "capitalismo salvaje", hecho a la medida de los pocos que se aprovechan de los demás hasta desdecir los principios de esa democracia que les da la oportunidad de enriquecerse ilimitadamente.

${ }^{6}$ Existen muchos libros escritos al respecto. István Hont, por ejemplo, en Politics in Commercial Society realiza un interesante estudio comparativo entre Rousseau y Adam Smith. Hont arguye que el capitalismo moderno no ha superado el grave temor rousseauniano de que al homo economicus liberal le falte, desde su origen, la directriz moral. La carencia de valores morales, preocupación que Rousseau comparte con Diderot, tiene mucho que ver con la pérdida del rumbo de las sociedades capitalistas. 
Es la lejana voz provinciana e inestable del Robinson rousseauniano que creo escuchar en la principal novela costumbrista boliviana: La chaskañawi, de Carlos Medinaceli. Adolfo Reyes, el personaje masculino central de la novela, muestra la debilitada condición del intelectual criollo que se desmorona y que sucumbe a la mediocridad del ambiente provinciano en el cual ha decidido vivir, escapando del falso mundo de la ciudad. Al dibujar a su personaje, Medinaceli revela no ser propiamente conservador porque no se congela en la añoranza del pasado colonial, pero, en consonancia con el Rousseau que acabamos de mostrar, tampoco es burgués, porque desprecia y combate la hipocresía y la egolatría creadas por dicha realidad.

Adolfo Reyes, vástago provinciano de tronco hispano, retorna de Sucre, donde estudia Derecho, al terruño de San Javier de Chirca. La visita al pueblo natal, supuestamente breve, para resolver trámites de la herencia, le cambia el rumbo de la vida. Agasajado en el pueblo por parientes y amigos, conoce a dos mujeres: una es Claudina García, chola que lo deslumbra con su donaire y vitalidad. Opuesta a la figura altiva y voluptuosa de la chola, aparece Julia Valdez, señorita de alcurnia de la sociedad provinciana, quien se casa con Adolfo.

Puesto que representan visiones de mundo diferentes, ambas relaciones amorosas no pueden ser más contrastantes. Julia y Adolfo quedan atados por los vínculos de sociabilidad estamental, ya debilitados a principios del siglo XX. Esta relación es incapaz de contener la arremetida de un cholaje independiente, pleno en vitalidad, como lo muestra Claudina, quien doblega la voluntad de Adolfo y destroza su matrimonio.

Me detengo acá para observar el comportamiento de Adolfo. Alejado de la ciudad y conmovido por el plácido paisaje campestre, exclama: "Sí, Juan Jacobo tenía razón: la naturaleza es buena y el hombre también es bueno, pero la sociedad lo ha corrompido" (Medinaceli 65). En este breve comentario, que no se repite, queda planteado - aunque también silenciado- el motivo rousseauniano del retorno a la naturaleza.

Medinaceli descompone y reconstruye este motivo literario con la desventura de Adolfo. El comportamiento del antihéroe de la novela contrasta

\footnotetext{
No es posible entender de otro modo la advertencia que Rousseau hace, en la Disertación sobre el origen y fundación de la desigualdad humana, donde afirma que, en medio de tanta filosofía, humanidad y civilización, los humanos no tenemos otra cosa que mostrar que nuestra frívola y engañosa apariencia, nuestro honor desprovisto de virtud, nuestra razón sin sabiduría, y nuestro deseo de sentir placer sin ocuparnos de buscar la felicidad (Hont 115).
} 
con la figura de Robinson. Si bien Adolfo alaba a Rousseau, su comportamiento se aleja del modelo humano ejemplificado por Crusoe. Adolfo es un señorito desorientado, temperamentalmente salvaje, cuyo retorno al campo culmina con una derrota, apartado de la industriosa soledad que da lugar al homo economicus.

Adolfo vuelve a ser el homo sylvestris, el salvaje europeo que se acerca en comportamiento al grossi bestioni descrito por Giambattista Vico. Un Robinson disfuncional y distópico, impetuoso y grosero debido al consumo de alcohol, violador de la que será su esposa. Recluido en el campo debido a su fracasada vida; amancebado con Claudina; pasivo y falto de ideales, es la triste sombra del Robinson anglosajón.

\section{El Robinson paródico}

Ni verdadera ni falsa, toda novela es un artificio literario dotado de reglas propias; un sistema complejo de relaciones que, sin dejar de ser parte de la realidad, cumple con la función paródica de deformarla y no simplemente de imitarla. Se podría incluso afirmar que la novela tiene algo de barroca cuando crea esa ilusión de realidad que es una de las características del Felipe Delgado.

Se afirmó ya que el mundo de la novela de Saenz es mágico, extraño y burlesco. Veremos, a continuación, dos ejemplos que parodian la realidad con la obversión lógica de los argumentos de los personajes de esta obra.

A la muerte de Virgilio Delgado, Felipe, que ha dejado la casa paterna para vivir en soledad, alquila un cuarto, desde donde el caminante entabla relación con otros seres igualmente excéntricos. Apadrinado por su tío Apolinar Borda, que "siempre anda metido con gente rara" (59), busca el consejo de don Nicolás Estefanic, quien fuera socio de Virgilio, y fugara con los fondos de la empresa rescatadora de minerales. Un arrepentido bellaco "con tonguito" (40), Estefanic le pide a Felipe que tenga cuidado en negociar con un brujo que aunque parezca ser una buena persona, da lugar a que uno se equivoque, puesto que "todo desatino tiene algún atractivo" (59). Este consejo es una suerte de reflexión bufa sobre el comportamiento del brujo Juan de la Cruz Oblitas, con quien Felipe desea entrar en sociedad.

Apolinar Borda relaciona a Oblitas con Felipe. La descripción de este bufo entendido en negocios y en ciencias ocultas, es algo ridícula. Oblitas se presenta ". . .con un saco ajustado hasta más no poder, por lo que los brazos se mantenían rígidos y considerablemente separados del cuerpo, dando una impresión muy chistosa y extraña" (62). Después de este risible encuentro, y 
superada la afrenta del pellizco del cachete, ambos personajes, que siguen los buenos oficios de don Apolinar Borda, entablan diálogo para crear un negocio, asociándose con aportes de capital. Oblitas propone crear una sociedad mercantil con todas las reglas del caso. Este mago entiende a la perfección la naturaleza de los contratos mercantiles y las obligaciones civiles y comerciales que de ellos emanan. Oblitas hace notar que "se trata [...] de una sociedad comercial a secas. Como usted comprenderá, una sociedad comercial puede abarcar actividades muy amplias, o bien muy restingidas" (71). Terminada de mostrar la constitución de la sociedad mercantil, Oblitas añade una segunda propuesta, relacionada con el objeto del contrato. Éste choca con la razón y torna inverosímil el acuerdo de las partes. La sociedad se vuelve disparatada cuando especifica que el objeto será "el rescate de corderos y la fabricación de fuegos artificiales" (71). Oblitas revela el propósito con acartonada seriedad, hecho que también pone en duda su cordura. El comerciante y mago asegura a Delgado una renta mensual fija, pero a éste parece no interesarle el tema, como tampoco las garantías "reales y materiales", incluyendo la primera hipoteca que gravaría uno de los inmuebles de Oblitas. A las propuestras de Oblitas, Felipe añade otra observación disparatada que vuelve a desestabilizar la seriedad del contrato: "Ya lo veo - dijo Delgado, con tono vacilante, y añadió-: Pero eso de ganar plata sin mover un dedo no me gusta" (72). Oblitas hace oídos sordos al reparo y se focaliza en las condiciones del contrato, particularmente en la necesidad de delimitar el monto de los aportes de capital: ocho mil bolivianos como mínimo, y veinte mil como máximo. Delgado aprueba el monto y Oblitas intenta trabar el cuasi-contrato de la litis, es decir, el perfeccionamiento del contrato con la respuesta de Delgado. Pero éste pone en duda una vez más la seriedad del contrato con la obversión lógica del argumento. Delgado rechaza las garantías ofrecidas por Oblitas: "No quiero garantías de ninguna clase; no necesito casas, ni hipotecas, ni documentos, ni recibos, ni juramentos, ni papeles, ni nada en absoluto. Si yo entro en sociedad es porque me da la gana" (73). Y añade que, siendo hombre de principios, "si me salta usted con cuentos y no me devuelve mi plata cuando yo se la pida, lo mato" (73).

Las respuestas dadas por Delgado, formas del comportamiento irracional de alguien que ha perdido el sano juicio debido a los efectos del alcohol, o a una combinación de locura y alcohol, concluyen con la decisión de que el negocio se llevará a cabo sin que las garantías necesarias queden consensuadas por las partes, y sin que el objeto del contrato convenza racionalmente. El negocio se transforma en una risible parodia de los actos jurídicos promovidos por probables interdictos, es decir, lo obverso del rol 
cumplido por el homo economicus, motor del progreso y de la conquista de la modernidad. Como lo expresa Oblitas: "el progreso es depravación" (70). De este modo, la parodia queda completa con el negocio fracasado que, de acuerdo con Oblitas, se debe a la adversidad producida por "la mala fe en el mercado de la demanda y la buena fe en el mercado de la oferta" (100). Ante tan lamentable desequilibrio, Oblitas da a Delgado dos opciones: recuperar el dinero que Oblitas está dispuesto a devolver, o doblar la inversión de capital. Ante el asombro de Oblitas y del tío Apolinar, Delgado decide no ocuparse más del asunto, cediéndole al tío todo el capital heredado. Tío y socio estallan jubilosos ante la inesperada y grotesca decisión, también obversa porque "el júbilo no podía darse como alegría sino como espanto. El espanto en cuanto se manifiesta lo desmedido" (102). Retomaré, al final del trabajo, este júbilo espantable como la situación racionalmente incomprensible que reúne el horror y la risa, esencia de lo "grotesco jubiloso".

El segundo caso aquí seleccionado como parodia del homo economicus de la modernidad, tiene que ver con la peculiar alegría manifestada por los allegados a Delgado en el lugar de reunión: "El purgatorio", la bodega de Corsino Ordoñez.

Felipe, el caminante que prosigue sus marchas nocturas "sin trazarse plan alguno", y sin saber adónde va, deja que las calles lo lleven al oscuro callejón de la calle Inquisivi, donde reaparece el "viejo pestilente", la figura amenazadoramente conocida que siempre puede estar a la vuelta de la esquina, defecando, cobijado en el escalón de una casa o en el interior de un portal. Huyendo de esta figura, ahora vestida de payaso, Delgado apresura el paso hasta desembocar en la Avenida Pando, y caminar por laberínticas calles que lo llevan a la bodega, donde, en medio del velorio de la nieta del camarero, conoce a Román Peña y Lillo, el "impecable pordiosero", miembro de ese mundo de aparapitas, los auténticos Robinsones urbanos. Efectivamente, el jorobado Peña y Lillo, Indalecio Beltrán y El Delicado, son ejemplos de los Robinsones urbanos que pueblan este mundo de beodos consuetudinarios, y que, en la mayoría de los casos, son seres envueltos en harapos hediondos, porque se mean y vomitan encima y apenas se molestan en limpiarse. A veces miran con atención, con ojos penetrantes, pero no hablan mucho ni piden limosna, y caminan por barrios laberínticos y ocultos como ese Robinson envuelto en pieles que les antecede, solos en las calles o en la oquedad de la bodega como en una isla donde no viviera nadie más, alimentándose del alcohol que ingieren. Todos estos seres viven el júbilo bajo la obversión lógica 
de su leitmotiv "cuando se muere viviendo, no se vive muriendo; y cuando se bebe muriendo, no se muere bebiendo" (112).

Delgado se presenta e identifica "como corresponde a todo caballero" (113). En la reunión, encuentra que los harapientos, incluyendo el fantasma del viejo, detectado por su mal olor, son los únicos que "saben conducirse con decencia" (114). Horas después de haber consumido alcohol, Delgado tiene un sueño aterrador: se ha metamorfoseado en una mosca que observa, desde lo alto, el saco de uno de los aparapitas, lleno de remiendos de toda forma y color. La pesadilla que sufre es irreal, pero los remiendos del saco de aparapita son reales, hecho que da lugar a la exploración de uno de los temas más interesantes de la novela.

Una mezcolanza de telas, este conjunto de remiendos tiene solo "el color del tiempo" (142) y la cualidad de estar bien cosido con los más diversos materiales: "hilo, pita, cordel, cable eléctrico, guato de zapato, alambre o tiras de cuero" (143). Con una mezcla de terror y de repulsión, Delgado mira este saco "como un tejido vivo" (143). Curioso y deslumbrado, intenta adueñarse del saco, pero en el sueño se da cuenta de que uno debe ser un aparapita auténtico para poder usarlo, y que "nadie podía ser aparapita así porque sí, con solo querer y desear, sino que era cuestión de poder y de merecer" (143).

Verdaderos filósofos de la "desproporción del vivir y la vida" (22), los aparapitas beben hasta más no poder. Intoxicados, se vuelcan a la calle para "sacarse el cuerpo", es decir, para "sacudirse este hechizo del vivir" (22). Esta "esperanza sin esperanza" solamente puede ser alcanzada en este momento extraordinario que es el "sacarse el cuerpo", enrevesada lógica de ver la vida y la muerte desde el júbilo de los marginales que no pueden ni deben llamarse ciudadanos, sino excéntricos migrantes aymaras del campo a la ciudad. "Anarquistas natos", los aparapitas dejan de ser indios, para hacer y deshacer de la ciudad en la que habitan, mofándose "de aquella otra ciudad" que los envilece (149).

Puesto que estos Robinsones urbanos solamente pueden ser explicados "con los ojos del alma" (155), su originalidad reside en ese "sacarse el cuerpo" como un acto de locura y de liberación. Es el máximo ritual del "grotesco jubiloso"que ahora paso a explicar.

En una entrevista que se me hizo hace catorce años, propuse el "grotesco jubiloso"(PIEB 2) como un espacio estético de la tensa relación entre lo rural y lo urbano. Mi propuesta sobre los claroscuros de lo grotesco social boliviano -me refiero acá a un asunto estético, diferente de lo que se conoce en el pensamiento social como "lo abigarrado" - es también recuperado tanto 
en los trabajos de investigadores mexicanos, como Armando Bartra, y de bolivianos, como Juan Carlos Orihuela y Gonzalo Rojas. Todos ellos se refieren a esta noción con la finalidad de ahondar en lo que Armando Bartra llama "la grotescidad" (Bartra 218), es decir, la capacidad de desquiciar todas las jerarquías y, así, de subvertir la realidad. Esta grotescidad, es el "actuar como locos" (206) que pone las cosas al revés, una manera de trastocar el mundo racional por otro: el mundo vuelto extraño, como sucede en la novela de Saenz. Más que un estilo, el grotesco jubiloso es un ánimo y una intención de vencer toda la sabiduría racional del mundo Por eso no hay clásicos en un grotesco, ni tampoco un canon. Por ello la novela de Saenz es una exploración muy particular del underground paceño, a medio camino entre el horror y la risa.

Desmedida y excéntrica es la vida de Felipe Delgado, como también es grotesca la estrategia que adopta Saenz para impulsar el caminar solitario de su Robinson urbano. El interactuar de Felipe con otros personajes, sujeto a la obversión lógica de los argumentos, ofrece una no-visión grotesca y subversiva del mundo, que es imposible imitar. Podría decirse que el grotesco jubiloso es una lúdica arremetida de lo excéntrico, de lo marginal, contra el poder, mediante la apropiación paródica de los símbolos y de los valores dominantes. Esta capacidad de desquiciar las jerarquías y de subvertir la realidad no corresponde a la condición abigarrada o barroca del orden social boliviano, sino, como afirma Bartra, a su carácter "torcido, contrahecho, monstruoso" (224).

Va por mal camino quien piensa que Saenz avala los conceptos de cohesión social -estado, nación, sociedad- porque su novela va a contracorriente de todo ello, inclusive cuando exalta y a la vez parodia a Tamayo, el pensador nacional por excelencia. Es el nihilismo existencial que reclama la atención de Saenz, sujeto al rol subversivo del anárquico exceso; al lado potencialmente desquiciante de la desproporción, de la paradoja y de la risa. De igual modo, la obsversión lógica que Felipe Delgado imprime a sus argumentos tiene mucho que ver con el modo en que el personaje enfrenta el orden social e institucional que lo subsume y a la vez rechaza, lo incluye y al mismo tiempo excluye. Es por ello que el personaje "se está" en una exterioridad que, en definitiva, es estigma y también bendición.

Felipe Delgado, otro de los Robinsones, podría ser tenido como una mutación, quizás la más actual, del Robinson de Defoe, esa extraordinaria transfiguración moderna del viejo mito del hombre salvaje, tema al que se refieren los trabajos etnológicos de Roger Bartra. Pero si Robinson es llevado 
por Defoe a una existencia salvaje para demostrar la posibilidad de vencer el estado de naturaleza con la creación del homo economicus del capitalismo, Saenz plantea en su novela la existencia imaginaria no solo de otro Robinson -es el caso de la figuración del Robinson disfuncional de la novela del encholamiento- sino de un Robinson otro, paródico, anárquico, excéntrico, clarividente arrepentido de todo lo que tenga que ver con el porvenir. Este Robinson nace para la noche, espacio y tiempo que, como muchos críticos han observado, permite a Delgado hurgar en el corazón de la memoria de la ciudad de La Paz.

\section{Bibliografía citada}

BARTRA, Armando. 2011. Tiempo de mitos y carnaval. Indios, campesinos y revoluciones. México D.F.: Editorial Ítaca.

BARTRA, Roger. 2014. El mito del salvaje. México: Fondo de Cultura Económica.

BENJAMIN, Walter. Selected Writings. 2003. 4 vols. Michael Jennings et.al., eds. Rodney Livingstone and Edmund Jephcott, trads. Cambridge, MA.: Belknap Press.

DUNKERLEY, James. 2019. Crusoe and his Consequences. New York, London: OR Books.

FRANZEN, Jonathan. 2011. "Farther Away. Robinson Crusoe, David Foster Wallace, and the Island of Solitude". New Yorker 18 (April): 81-88.

HONT, István. 2015. Politics in Commercial Society: Jean-Jacques Rousseau and Adam Smith. Béla Kaposy y Michael Sonenscher, eds. Cambridge MA.: Harvard University Press.

KAYSER, Wolfgang. 1963. The Grotesque in Art and Literature. Ulrich Weinstein, trad. Bloomington, Indiana: University Press.

MEDINACELI, Carlos. 1967 [1947]. La chaskañawi. La Paz, Editorial Juventud.

MISHRA, Pankaj. 2016. "Down with Élites! Rousseau in the Age of Trump and Brexit". New Yorker (Printed edition, August 1). 68-71.

MUÑOZ Molina, Antonio. 2009. Sefarad. Barcelona: Seix Barral.

PAREJA, Roberto. 2014. Entre caudillos y multitudes. Modernidad estética y esfera pública en Bolivia, siglos XIX y XX. Madrid: Iberoamericana Vervuert.

PIEB. 2007. "El mestizaje en tiempos de indigenismo". Temas de debate. Víctor Orduna, ed. Boletín del Programa de Investigación Estratégica en Bolivia 8 (4): 1-4.

RODRÍGUEZ GARCÍA, Huáscar. 2012. La choledad antiestatal. EI anarcosindicalismo en el movimiento obrero boliviano (1912-1965). La Paz: Muela del Diablo editores.

SAENZ, Jaime. Felipe Delgado. La Paz, Difusión Ltda, 1980. 
WATT, Ian. 1957. The Rise of the Novel. Berkeley, CA.: University of California Press.

\section{$(c)$ EY}

\section{ULS D-Serle? $\begin{aligned} & \text { This journal is published by the University Library System of the } \\ & \text { University of Pittsburgh as part of its D-Scribe Digital Publishing }\end{aligned}$ Program, and is cosponsored by the University of Pittsburgh Press.}

